\title{
Structure-toxicity Relationship in Subunit Structure of Ricin $\mathrm{D}^{\dagger}$
}

\author{
Kenji Hara, Masatsune Ishiguro, Gunki Funatsu \\ and Masaru Funatsu \\ Laboratory of Biochemistry, Faculty of Agriculture, \\ Kyushu University, Fukuoka 812, Japan
}

Received April 8, 1975

\begin{abstract}
The re-formation of the single disulfide bond which linked two polypeptide chains of ricin D was studied. Ricin D was reoxidized preferentially by the air-oxidation of its reduced polypeptide chains in a yield of $74 \%$ with the recovery of full toxicity. Furthermore ricin D was completely regenerated from its compound with $p$-chloromercuribenzoate. It seems reasonable to assume that the toxicity of ricin $D$ arises from the quaternary structure of ricin D molecule.
\end{abstract}

Previous communications have reported on the reduction of a single disulfide bond that linked two polypeptide chains of ricin $\mathrm{D}$, a toxic glycoprotein of the castor bean seeds, ${ }^{1}$ ) by treatment of the native protein in the absence of urea with $\beta$-mercaptoethanol. Since the specific reduction of the single disulfide bond resulted in a marked decrease in toxicity, it seems reasonable to assume that the toxicity of ricin $\mathrm{D}$ arises from the quaternary structure of ricin $\mathrm{D}$ molecule. ${ }^{2}$ Thus, it has been observed that reduced ricin D contains no new amino-terminal amino acids, and that its molecular weight and amino acid content (after alkylation of the SH groups) are in accord with the expected values. ${ }^{3)}$ It is therefore possible to study the re-formation of a single disulfide bond and to examine the influence of chemical modifications on the efficiency of reoxidation and retoxication.

The present paper deals with the regeneration of ricin D with the recovery of full toxicity from its reduced ricin $D$ by air-oxidation and with the regeneration of reduced ricin $D$ from its compound with $p$-chloromercuribenzoate (PCMB).

$\dagger$ Biochemical Studies on Ricin. Part VII. Previous paper: K. Hara, M. Ishiguro, G. Funatsu and M. Funatsu, Agr. Biol. Chem., 39, 1631 (1975).

\section{MATERIALS AND METHODS}

Materials. Ricin D used throughout this study was purified as described in the preceding paper. ${ }^{4}$ All reagents used were of analytical grade except the followings. DEAE-cellulose $(0.8 \sim 1.0 \mathrm{meq} / \mathrm{g})$ was obtained from Brown Co., Sephadex G-25 from Pharmachia Co., and Biogel P-4 (200 400 Mesh) from BioRad Laboratories.

Reduction of ricin D. Reduced ricin D was prepared according to the procedures described in a previous paper. ${ }^{11}$ In a typical experiment, $25 \mathrm{ml}$ of $1 \%$ ricin D solution were added in $25 \mathrm{ml}$ of $1.3 \mathrm{M}$ Tris- $\mathrm{HCl}$ buffer (containing $2 \mathrm{ml}$ of $5 \%$ EDTA solution) in the absence of urea, adjusted to $\mathrm{pH}$ 8.6. $\beta$-Mercaptoethanol was added at a level of $0.5 \%$ per protein solution, the container was flushed with nitrogen and the solution was allowed to stand for $2 \mathrm{hr}$ at $25^{\circ} \mathrm{C}$. After this period, an aliquot of the reduction mixture was withdrawn to estimate extent of reduction of the interpolypeptide chain disulfide bonds. After carboxymethylation of this aliquot with monoiodoacetic acid, hydrolysis was carried out at $106^{\circ} \mathrm{C}$ for $24 \mathrm{hr}$ and an aliquot of this solution was analyzed for carboxymethylcysteine (CM-cysteine) with a Hitachi Amino Acid Auto analyzer Model KLA-2B.

Reoxidation of reduced ricin $D$. The reduction mixture was then transferred into Visking casing $(\# 18$ / 32) and dialyzed with gentle stirring against $0.005 \mathrm{M}$ Tris-HCl buffer, $\mathrm{pH} 8.5$, containing $0.2 \%$ EDTA. Airoxidation of the reduction mixture was accomplished simultaneously by the removal of $\beta$-mercaptoethanol during $48 \mathrm{hr}$ dialysis at $4^{\circ} \mathrm{C}$ with several changes of outer buffer solution. 
Stabilization of protein $S H$ groups in a reversible form after reduction. In studies of the sulfhydryldisulfide relationships in ricin $\mathrm{D}, \mathrm{SH}$ groups are generally stabilized in a reversible form with suitable reagents such as PCMB. $10 \mathrm{mg}$ of reduced ricin $\mathrm{D}$ was adjusted to $\mathrm{pH} 3.5$ with glacial acetic acid and the entire solution was applied to a $1.5 \times 28.0 \mathrm{~cm}$ column of Biogel P-4 which had been throughly equilibrated with $0.1 \mathrm{M}$ acetic acid containing $10^{-3} \mathrm{M}$ EDTA. The reduced ricin $\mathrm{D}$ emerging from Biogel $\mathrm{P}-4$ column was treated with a 20 -fold excess of $6 \times 10^{-4} \mathrm{M} \mathrm{PCMB}^{5,6}$ (based on the moles of $\mathrm{SH}$ groups), and adjusted to $\mathrm{pH} 8.0$ with $\mathrm{NaOH}$. The final mixture was dialyzed against $0.005 \mathrm{M}$ Tris- $\mathrm{HCl}$ buffer at $\mathrm{pH} 8.5$ to remove excess PCMB. Regeneration of ricin $\mathrm{D}$ from its compound with PCMB was accomplished by adding $1 \mu \mathrm{l}$ of $\beta$-mercaptoethanol per $m g$ of derivative and passing the solution through the Sephadex G-25 column.

Polyacrylamide gel disc electrophoresis. Disc electrophoresis in polyacrylamide gel were performed by the method of Orstein. ${ }^{7}$ The procedures of polyacrylamide gel electrophoresis in sodium dodecyl sulfate for the determination of molecular weight were the same as those described in a preceding paper. ${ }^{4)}$ The marker proteins (cytochrome c, chymotrypsinogen A, aldolase, hen egg albumin and bovine serum albumin) for the determination of molecular weight were purchased from Boeringer Mannheim GmbH (Germany).

Determination of the lethal toxicity. For the determination of the lethal toxicity, pure-bred mice (ddN) weighing 20 grams were used according to our previously described procedure. ${ }^{8}$ A A sample solution, diluted appropriately with physiological saline, was injected intraperitoneally into mice and the results were observed at intervals of $24 \mathrm{hr}$. The minimum lethal dose at $48 \mathrm{hr}\left(\mathrm{MLD}_{48}\right)$ was adopted as a measure of toxicity and was expressed as $\mu \mathrm{g}$ protein nitrogen per gram body weight of mouse.

\section{RESULTS AND DISCUSSION}

\section{Reduction of ricin $D$}

After reduction of ricin $\mathrm{D}$, an aliquot was withdrawn for the determination of the degree of reduction. After carboxymethylation of this aliquot with monoiodoacetic acid, hydrolysis was carried out at $106^{\circ} \mathrm{C}$ for $24 \mathrm{hr}$, and 1.68 moles of CM-cysteine per mole of ricin $\mathrm{D}$ ( $84 \%$ reduction) was obtained. When the reduced and carboxymethylated product of ricin D (RoCM-ricin D) was subjected to disc electrophoresis in $7.5 \%$ polyacrylamide gel at $\mathrm{pH} 8.3$, it migrated in three bands as reported in the previous paper. ${ }^{11}$ From these results, it was inferred that a large part of ricin $\mathrm{D}$ contained in the reduction mixture could be dissociated into $\mathrm{SH}$-subunits.

\section{Reoxidation of reduced ricin $D$}

After air-oxidation of the reduction mixture, the air-oxidation products were subjected to a polyacrylamide gel disc electrophoresis at $\mathrm{pH}$ 8.3 with $7.5 \%$ standard gel. As seen in Fig. 1, three bands, one major and two minor bands were obtained. The yields of these bands were determined spectrophotometrically to be 78,11 and $11 \%$, respectively.

\section{Purification of air-oxidation products}

The products obtained by air-oxidation were then fractionated by DEAE-cellulose. After removal of any insoluble material by centrifugation, $10 \mathrm{mg}$ of the air-oxidation products was applied onto a DEAE-cellulose column previously equilibrated with $0.005 \mathrm{M}$ Tris- $\mathrm{HCl}$ buffer of $\mathrm{pH}$ 8.5. A linear gradient was performed utilizing the same buffer with an

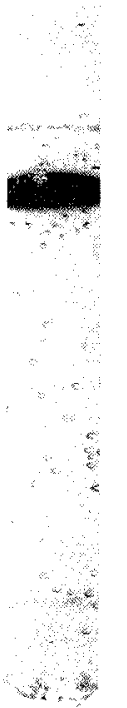

FIG. 1. Polyacrylamide Gel Electrophoretic Pattern of Regenerated Ricin D.

Electrophoresis was routinely performed with $2 \mathrm{~mA}$ per tube for $2.5 \mathrm{hr}$, and the proteins were stained with amido black $10 \mathrm{~B}$. Absorbance of stained bands in gel at $616 \mathrm{~nm}$ were recorded on a Atago Densitrol equipped with a recording device. 


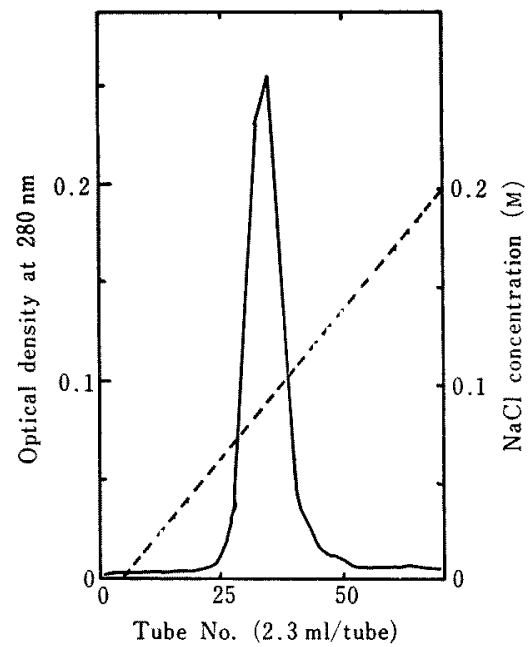

Fig. 2. Colunm Chromatogram of Crude Regenerated Ricin D on DEAE-cellulose.

Column size; $1.5 \times 16.0 \mathrm{~cm}$, Content of each tube; $2.3 \mathrm{ml}$, Flow rate; $30 \mathrm{ml} / \mathrm{hr}$. The dotted line represent the $\mathrm{NaCl}$ concentration. The solid line represent absorbance at $280 \mathrm{~nm}(1 \mathrm{~cm}$ cell).

increasing sodium chloride concentration from zero to $0.2 \mathrm{M}$. The reoxidized ricin $\mathrm{D}$ in the fraction $\mathrm{F}-1$ behaved homogeneously on DEAE-cellulose column chromatography as seen in Fig. 2. The reoxidized ricin D, fraction F-1, which corresponds to band 1 (Fig. 1) was eluted on rechromatography at the same concentration of sodium chloride solution as ricin $\mathrm{D}$.

\section{Characterization of reoxidized ricin $D$}

No CM-cysteine was detected after fraction F-1 was treated with monoiodoacetic acid at $\mathrm{pH} 8.5$ and hydrolysis was carried out at $106^{\circ} \mathrm{C}$ for $24 \mathrm{hr}$. Homogeneity of fraction $\mathrm{F}-1$ was established by polyacrylamide gel disc electrophoresis at $\mathrm{pH} 8.3$ and sedimentation velocity experiments. Disc electrophoresis indicated that fraction $\mathrm{F}-1$ is electrophoretically homogeneous and has the same relative mobility as ricin D. Fraction $\mathrm{F}-1$ was ultracentrifuged with a Spinco Model E Ultracentrifuge, operating at $52,640 \mathrm{rpm}$ at $20.0^{\circ} \mathrm{C}$. Fraction F-1 was homogeneous with a symmetric sedimenting boundary. The sedimentation coefficient, $s_{20, w}$ of the fraction F-1 was

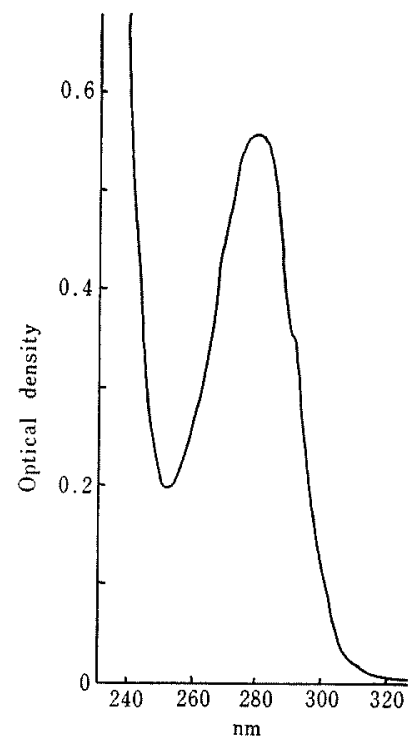

FIG. 3. Ultraviolet Absorption Spectrum of Regenerated Ricin D. (pH 8.5, 0.005 M Tris-HCl buffer)

calculated to be $4.40 \mathrm{~s}$, a value which corresponds to that of ricin D. ${ }^{8}$ Moreover, a typical absorption spectrum of fraction $F-1$ is shown in Fig. 3; the maximum and the minimum absorption were found at $280 \mathrm{~nm}$ and 251 $\mathrm{nm}$, respectively, and $E_{\mathrm{max}} / E_{\mathrm{min}}$ was 2.30 . These values and the spectrum are identical to those of ricin D. ${ }^{8}$

Stabilization of protein $S H$ groups after reduction in a reversible form

The reduced ricin $\mathrm{D}$ was applied to a column of Biogel P-4. The column was developed with the same solvent. The bulk of the protein emerged ahead of the reagents in the original mixture. The $\beta$-mercaptoethanol and salts appeared in a fraction entirely separated from the protein peak. An aliquot was withdrawn for estimation of the $\mathrm{SH}$ content. After carboxymethylation of this aliquot, it was found that a sample of protein contained $1.40 \mathrm{SH}$ groups per mole of reduced ricin $\mathrm{D}$. From these results, it was reasoned that $\mathrm{SH}$ groups of the reduced ricin $\mathrm{D}$ are stable in $\mathrm{pH}$ 3.3. The reduced ricin $\mathrm{D}$ emerging from the Biogel P-4 was treated with PCMB at $\mathrm{pH} 8.0$ and exhaustively dialyzed against $0.005 \mathrm{M}$ 


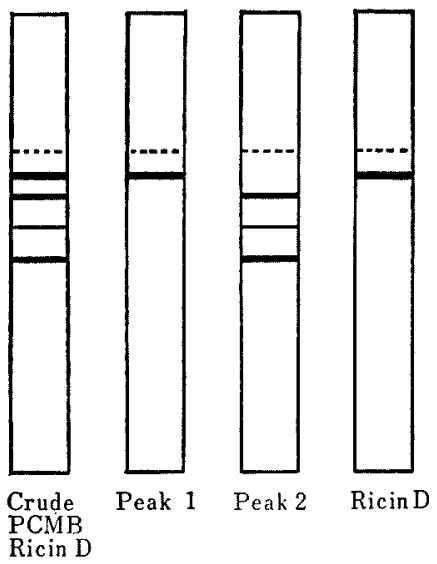

(A) Normal Disc-electrophoresis

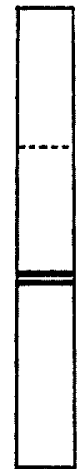

Peak 2

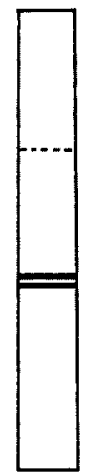

Ricin D

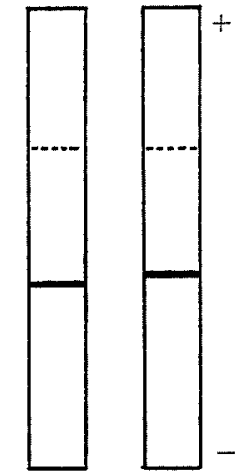

S-CM-Ile S-CM-Ala

(B) SDS-disc-electrophoresis

FIG. 4. Polyacrylamide Gel Disc Electrophoresis of PCMB-Ricin D and Its Derivatives (A) and Polyacrylamide Gel SDS Disc Electrophoresis (B).

Tris- $\mathrm{HCl}$ buffer at $\mathrm{pH} 8.5$ to remove excess PCMB. No precipitation was detected in the solution. This crude PCMB-ricin D was subjected to polyacrylamide gel electrophoresis at $\mathrm{pH}$ 8.3. As shown in Fig. 4-A, four bands (bands $a, b, c$ and $d$ ) were obtained. The band $a$ corresponded to native ricin $\mathrm{D}$, and the yields of band $a$ and other bands were determined spectrophotometrically to be 40 and $60 \%$, respectively. Crude PCMB-ricin D contained $40 \%$ native ricin D. Finally, PCMB-ricin D could to be purified by DEAEcellulose column chromatography. The $10 \mathrm{mg}$ dialyzed crude PCMB-ricin D solution was applied onto a DEAE-cellulose column, which had been equilibrated with $0.005 \mathrm{M}$ Tris- $\mathrm{HCl}$ buffer ( $\mathrm{pH}$ 8.5). The column was developed by linear gradient elution with a mixing chamber containing $75 \mathrm{ml}$ of $0.005 \mathrm{M}$ Tris- $\mathrm{HCl}$ buffer and a reservoir that contained $75 \mathrm{ml}$ of $0.20 \mathrm{M} \mathrm{NaCl}$ in the same buffer. As can be seen in Fig. 5, two peaks (peak 1 and peak 2) were obtained. The first fraction, peak 1, which corresponds to band $a$ was eluted at the same concentration of $\mathrm{NaCl}$ solution as ricin D and was homogeneous electrophoretically (Fig. 4-A). Peak 2, which corresponds to bands $b, c$ and $d$ (Fig. 4-A) by disc electrophoresis was subjected to $10 \%$ cross linkage SDS disc electrophoresis, it migrated as two bands, bands $e$ and $f$ (Fig.
4-B). The band $e$ corresponds to S-CMalanine chain and band $f$ to $\mathrm{S}-\mathrm{CM}$-isoleucine chain of ricin D. From these results it was concluded that peak 1 was native ricin $\mathrm{D}$ and peak 2 was PCMB-ricin D, which consisted of PCMB-alanine and PCMB-isoleucine chains. The peak 2 migrated as three bands, it was presumed that one of which may represent the combination of PCMB-alanine and PCMBisoleucine chains, whereas the other two bands could be isolated PCMB-alanine and PCMB-isoleucine chains. A typical absorption spectrum of the peak 2 is shown in Fig. 6 ; the maximum and the minimum absorption are found at $308 \mathrm{~nm}$ and $260 \mathrm{~nm}$, respectively.

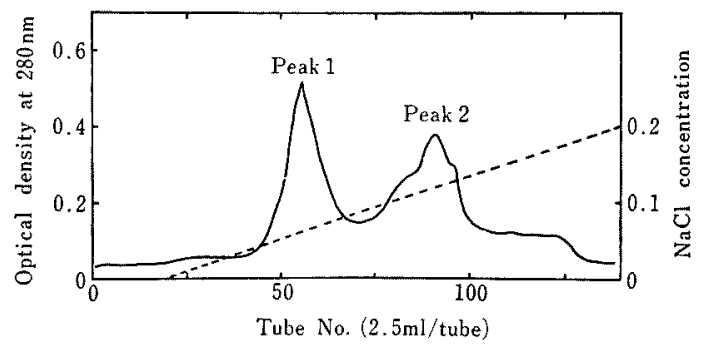

FIG. 5. Column Chromatogram of Crude PCMBRicin D on DEAE-Cellulose.

Column size; $1.5 \times 20 \mathrm{~cm}$, Content of each tube; $2.5 \mathrm{ml}$, Flow rate; $30 \mathrm{ml} / \mathrm{hr}$. The dotted line represent the $\mathrm{NaCl}$ concentration. The solid line represent absorbaice at $280 \mathrm{~nm}(1 \mathrm{~cm}$ cell). 


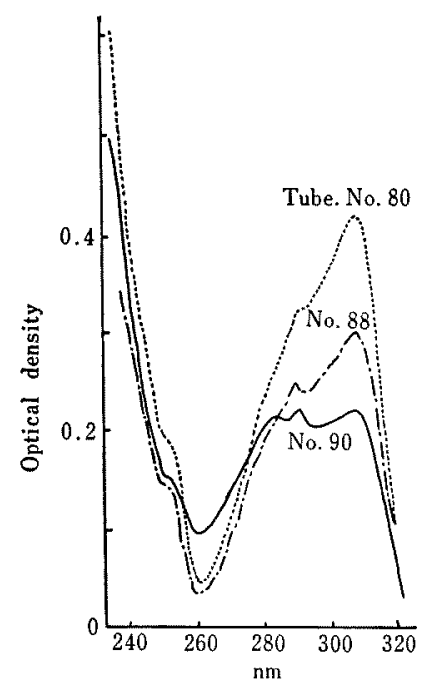

FIg. 6. Ultraviolet Absorption Spectrum of PCMBRicin D.

Reading from up curves are from Fig. 5, tube number of 80,88 and 90 , respectively $(\mathrm{pH} 8.5,0.005 \mathrm{M}$ Tris$\mathrm{HCl}$ buffer).

\section{Regeneration of ricin $D$ from its compound with $P C M B$}

The PCMB-ricin D (peak 2) was concentrated and $\beta$-mercaptoethanol ( $1 \mu \mathrm{l}$ per $1 \mathrm{mg}$ protein) was added. After standing for $30 \mathrm{~min}$, the solution was passed through a column of Sephadex G-25 previously equilibrated with $0.005 \mathrm{M}$ Tris-HCl buffer ( $\mathrm{pH} 8.5$ ). The column was developed with the same buffer. The protein peak (regenerated ricin D) entirely separated from the $\beta$-mercaptoethnol. A typical absorption spectrum of this regenerated ricin $\mathrm{D}$ is shown in Fig. 7; the maximum and the minimum absorptions are found at $280 \mathrm{~nm}$ and at $251 \mathrm{~nm}$, respectively, and $E_{\max } / E_{\min }$ was 2.30 . These values and the spectrum are identical to those of ricin $D^{8}{ }^{8}$ It was also found that the regenerated ricin $\mathrm{D}$ migrated as two bands, one major and other minor bands. The yields of these bands were determined spectrophotometrically to be 95 and $5 \%$, respectively. The main component had same relative mobility as that of ricin $\mathrm{D}$.

Physiological properties of the reoxidized ricin $D$

As presented in Table I, the minimum lethal

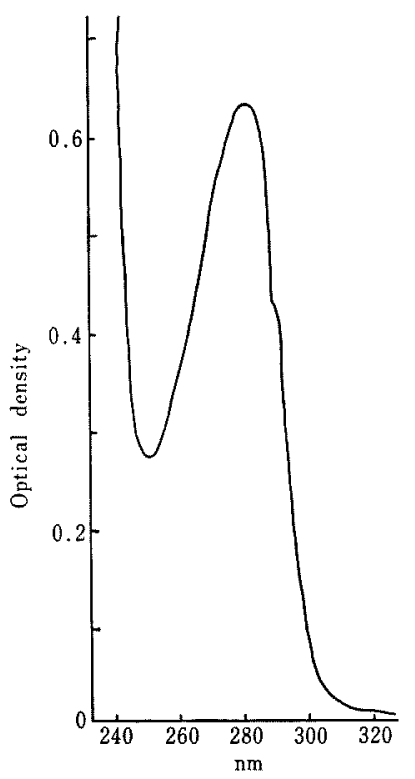

FIG. 7. Ultraviolet Absorption Spectrum of Regenerated Ricin D from Its Compound with PCMB (pH 8.5, 0.005 M Tris-HCl buffer).

TABle I. Toxicity of Reoxidized Ricin D (Fraction F-1)

\begin{tabular}{cccc}
\hline $\begin{array}{c}\text { Dose } \\
(\mu \mathrm{g} \cdot \mathrm{N} / \mathrm{g})\end{array}$ & $24 \mathrm{hr}$ & $48 \mathrm{hr}$ & $72 \mathrm{hr}$ \\
\hline 0.00379 & $4 / 5^{a)}$ & $5 / 5$ & \\
0.00190 & $3 / 5$ & $5 / 5$ & \\
0.00095 & $0 / 5$ & $3 / 5$ & $4 / 5$ \\
0.00002 & $0 / 5$ & $0 / 5$ & $0 / 5$ \\
\hline $0.85 \% \mathrm{NaCl}$ & $0 / 5$ & $0 / 5$ & $0 / 5$ \\
\hline$a 1 \quad X / Y: X$ and $Y$ represent the number of mouse \\
\multicolumn{4}{l}{ died and used for experiment, respectively. }
\end{tabular}

dose of reoxidized ricin $\mathrm{D}$, fraction $\mathrm{F}-1$, was $0.001 \mu \mathrm{g}$ protein nitrogen per gram body weight of mouse when injected intraperitoneally. This value corresponds to that obtained from ricin $D$ as reported previously. ${ }^{3,81}$

From these results of physical and physiological properties, it was concluded that ricin $\mathrm{D}$ itself was reoxidized preferentially by the air-oxidation of its reduced polypeptide chains in a yield of $c a .74 \%$.

Physiological properties of the PCMB-ricin D and regenerated ricin $D$ from its compound with $P C M B$ 
Table II. Toxicity of PCMB-RICIN D AND REGENERATED RICIN D FROM ITS COMPOUND WITH PCMB.

\begin{tabular}{lclll}
\hline \multicolumn{1}{c}{ Sample } & $\begin{array}{c}\text { Dose } \\
(\mu \mathrm{g} \cdot \mathrm{N} / \mathrm{g})\end{array}$ & $24 \mathrm{hr}$ & $48 \mathrm{hr}$ & $72 \mathrm{hr}$ \\
\hline \multirow{2}{*}{ PCMB-ricin D } & 0.0320 & $5 / 5^{a}$ & & \\
& 0.0160 & $2 / 5$ & $4 / 5$ & \\
& 0.0080 & $0 / 5$ & $4 / 5$ & \\
& 0.0040 & $0 / 5$ & $2 / 5$ & $3 / 5$ \\
& 0.0032 & $0 / 5$ & $0 / 5$ & $1 / 5$ \\
\hline \multirow{2}{*}{ Regenerated } & 0.0060 & $4 / 4$ & & \\
ricin D & 0.0030 & $3 / 4$ & $4 / 4$ & \\
& 0.0010 & $0 / 4$ & $2 / 4$ & $3 / 4$ \\
\hline $0.85 \% \mathrm{NaCl}$ & 0.0006 & $0 / 4$ & $0 / 4$ & $0 / 4$ \\
\hline
\end{tabular}

a) $X / Y$ : Same as described in Table I.

As presented in Table II, the minimum lethal dose of crude PCMB-ricin D (before purification with DEAE-cellulose column chromatography) and regenerated ricin $\mathrm{D}$ from its purified PCMB-ricin D were $0.004 \mu \mathrm{g}$ and $0.001 \mu \mathrm{g}$ protein nitrogen per gram body weight of mouse, respectively, when it was injected intraperitoneally into mice. Regenerated ricin D is as toxic as that of ricin $\mathrm{D}$ reported previously. ${ }^{3,8}$ The toxicity of crude PCMB-ricin D was $25 \%$ that of ricin D. The mixture of crude PCMB-ricin D contained $40 \%$ native ricin $\mathrm{D}$ (Fig. 4-A), therefore the toxicity of crude PCMB-ricin D comes from the contamination by native ricin $\mathrm{D}$.

The toxicity was markedly decreased by cleavage of the ricin D molecule into subunits. ${ }^{3}$ ) But the reduced ricin D and PCMB-ricin D was regenerated completely with full toxicity. Consequently, it seems reasonable to assume that the toxicity of ricin $\mathrm{D}$ arises from the quaternary structure of the ricin $\mathrm{D}$ molecule.

Acknowledgements. The authors are indebted to Dr. Victor G. Glushko for his comments.

\section{REFERENCES}

1) M. Funatsu, G. Funatsu, M. Ishiguro, S. Nanno and K. Hara, Proc. Japan Acad., 47, 718 (1971).

2) M. Funatsu, "Proteins, Structure and Function," Vol. II, Kodansha Ltd., Tokyo, and John Wiley and Son's, New York-London-Sidney-Toronto, 1972, p. 104.

3) K. Hara, M. Ishiguro, G. Funatsu and M. Funatsu, Agr. Biol. Chem., 39, 1631 (1975).

4) K. Hara, M. Ishiguro, G. Funatsu and $M$. Funatsu, ibid., 38, 65 (1974).

5) T. Takagi, Protein, Nucleic acid, Enzyme (Tokyo), 9, 1337 (1964).

6) T. Takagi, ibid., 10, 13 (1965).

7) L. Orstein, Ann. New York Acad. Sci., 121, 321 (1964).

8) M. Ishiguro, T. Takahashi, K. Hayashi and M. Funatsu, J. Biochem. (Tokyo), 56, 325 (1964). 